\title{
Digitalization and Decolonizing Education: A Qualitative Study of University of South Africa (UNISA) Leadership
}

\author{
Vuyisile Msila
}

\begin{abstract}
The COVID-19 pandemic that shook the world in 2020 forced all educational institutions to search for new ways of teaching and learning. Furthermore, education institutions such as the University of South Africa (UNISA), like all other universities, found themselves with a huge task of promoting digitalization. As a traditional distance education institution, UNISA had to refine digitalization in a time of decolonization in the Global South. This case study examined the role of educational managers in sustaining effective digitalization. Eight UNISA managers were selected and interviewed to understand how they perceived the role of digital leaders. Furthermore, the study sought to understand why it is critical that managers should be in the forefront of digitalization. The study found that at present in Africa it is critical for digitalization to be combined with decolonization. Additionally, when digitalization and decolonization are implemented simultaneously, they become vehicles for social justice and democracy. This then means that education can be a tool for liberation and achievement where the digital divide is minimized. When implemented well, education institutions become institutions with access for success. The conclusions show that a set strategy based on a new vision for a university will harness digital leadership. The participants also mentioned strategic documents at the university; on the one hand are the Five Pillars of Change whilst on the other are the Eight Dimensions of Transformation. Furthermore, the participants claimed that their institution was on the road to success whilst building UNISA as an institution "Towards the African University that builds futures."
\end{abstract}

Index Terms-Decolonization, digitalization, digital leadership, institutional culture, open universit.

\section{INTRODUCTION}

Beaudoin [1] declares that the current times have necessitated that higher education institutions embrace digitalization in their teaching and learning approaches. Yet he also adds that challenges such as lack of resources, strategic planning and effective management are huge hindrances to meaningful digitalization in many African institutions. If institutions cannot infuse digitalization as they integrate new systems, they are likely to continue with "the continuation of colonial-era, print-dependent educational practices" [1]. Msila [2] writes how a South African university needs to transform the institutional culture as it introduces a paradigm shift to enable student access, success and equity that would be supported by professional development of teachers. Mays [3] takes us through the

Manuscript received January 8, 2021; revised June 12, 2021.

The author is with Thabo Mbeki African School for Public and International Affairs, University of South Africa, South Africa (e-mail: msivuy@gmail.com). "generations" that UNISA has gone through over the years:

Table I shows how UNISA has been gradually transforming over the decades since its inception in 1873. Mays demonstrates how it started with the first generation which was a correspondence college with students expected to send assignment back and forth. The second generation emphasized study manuals and materials for self-study. Many students used these for rote learning. The third generation was still focused on print media but now there was some form of two way communication between the student and the lecturer. Then fourth and fifth generations allude to the gradual introduction of technology. In fact, UNISA was a correspondence university, and then became a distance education institution before it became an Open Distance Learning (ODL) university, but now labels itself as an Open Distance and e-Learning (ODeL) institution. Yet, despite its evolution, it still faces challenges as it tries to be a fully digital institution.

TABLE I: UNISA GENERATIONS (ADAPTED FROM MAYS, 2004)
\begin{tabular}{|l|l|}
\hline $\begin{array}{l}\text { First } \\
\text { generation }\end{array}$ & Correspondence: mailing systems \\
\hline $\begin{array}{l}\text { Second } \\
\text { generation }\end{array}$ & $\begin{array}{l}\text { Specially prepared self-study: material development, } \\
\text { storage, dispatch }\end{array}$ \\
\hline $\begin{array}{l}\text { Third } \\
\text { generation }\end{array}$ & $\begin{array}{l}\text { Print and multi-media as well as two-way } \\
\text { communication for teams/ learner support }\end{array}$ \\
\hline $\begin{array}{l}\text { Fourth } \\
\text { generation }\end{array}$ & $\begin{array}{l}\text { ICTs and two-way interaction: } \\
\text { learning/multi-skilling }\end{array}$ \\
\hline $\begin{array}{l}\text { Fifth } \\
\text { generation }\end{array}$ & $\begin{array}{l}\text { Communities of learning: } \\
\text { multi-skilling/decentralized decision-making }\end{array}$ \\
\hline
\end{tabular}

In his book, UNISA: The making of a distance learning university, Mason [4] unmasks the history of the university over decades and highlights the challenges posed by transformation and decolonization in the more recent years. Whilst UNISA's mantra is, Towards an African University, UNISA's past based on colonization and apartheid (Afrikaner nationalism), still looms large. Like all universities in South Africa, transformation has to contend with past social ills. The introduction of digitalization seeks to transform the conventional order as universities explore new generation options. The obstacle in most South African universities however, has been the absence of digital leadership styles [5] The skill or ability to lead efficiently in times of digitalization is pivotal in transforming institutions of higher learning in South Africa. This means that the efficacious application of digital leadership will enhance the digital acumen of colleagues and improve organizational performance [5].

This case study examines a sample of UNISA leaders' digital leadership styles in a time of decolonization. It also claims that it would be difficult to speak about digitalization in Africa without shedding light on the decolonization 
project. The Fallist Movements led by students in 2015 and 2016 have demonstrated how transformation is entangled with decolonization. In 2015/2016 university students stood up to fight for a decolonized system of education as well as the scrapping of university fees.

Two major questions were posed for this case study:

- What knowledge is critical to digital leaders at higher education institutions in a digital age?

- Secondly, why and how should university leaders be in the forefront of transformation and decolonization initiatives?

\section{DEFINITION OF TERMS}

Decolonization is the process of removing colonial elements. It is the advanced stage of self-knowledge and self-determination as Africans. In education when people decolonize, they bring the marginalized cultures and identities to the centre. Decolonising is also a realization that Europe is a province and that all knowledges matter and not the Western knowledges only. When we speak of the centre of knowledge it needs to include all knowledges.

Digital leadership is a form of leadership necessary for the new information age. Goethals, Sorenson and Burns [6] define digital leadership as core competence in communication, content and computing as a contribution toward knowledge society. Digital leaders help drive the digital transformation and in a time of decolonization it may be inevitable for them to be decolonization leaders as well, although the two are not necessarily intertwined. Zupancic, Verbeke, Achten and Herneoja [7] define digital leadership on two levels; on the one hand it refers to a particular skill that allows a leader to push the frontiers of design whilst on the other it encompasses the "skill of a person to advance game-changing technologies in a design team or organization."

Digitalization refers to the adoption of digital technologies instead of analogue or offline systems such as paper or whiteboards. Urbach and Roglinger [8] point out that digitalization presents huge challenges for organizations and business models to digitally transform themselves. Schumacher, Sihn and Erol [9] explain that digitalization describes the "social implications of computer-assistance, new media and communication platforms for economy, society and culture". The concept of 'digitalization' is different from 'digitization' which alludes to creating a digital representation of physical objects or attributes. Scanning an article and saving it as PDF, for example, is an illustration of digitization. Schumacher et al. [9] describe digitization as a concept that describes the "conversion of continuous analog, noisy and smoothly varying information into clear bits of $1 \mathrm{~s}$ and $0 \mathrm{~s}$ ".

\section{Digitalization AND DECOLONIZATION IN AFRICAN INSTITUTIONS}

Digitalization in education institutions could not eschew the debates on decolonization in South Africa. The calls of the Fallist Movements in 2015 and 2016 were calling for a total overhaul of higher education institutions, thus preparing them for post-colonial systems beyond colonial and apartheid education systems. Chukwuere [10] contends that the decolonization process can never be complete without the recognition of indigenous knowledge systems and their integration into digitalization. Therefore, concepts such as Africanization, decolonization and indigenization will make sense in the current transformation if they connect with digitalization because technology has arrived as well. For several scholars decolonization should address Western hegemony and epistemic violence as it brings African knowledges to the centre [11, [12]. This means that any framework of digitalization should address Africanization, decolonization and indigenization or else it would not be able to address transformation towards technologies that accommodate culture [13], [14]. More than two decades after apartheid education, continuing debates reflect Western hegemony and this includes both higher and basic education institutions. Therefore, if technology is to support transformation it needs to fight many ills. The biggest of these ills is the continued marginalization of indigenous knowledges. Holev [15] points out that the use of technologies is characterized by power structures and developing countries thus need to address digital colonialism as they bring equity into the implementation of technologies. "All users were supposed to be equal behind the mask of anonymity, and therefore everyone was meant to have equal rights. No hierarchies - including amongst users from different countries" [15]. There should always the conscious effort to avoid what Holev [15] refers to as "digital or electronic colonialism".

In the decolonization age people need to think clearly about the role of digitalization in society. The digital age in South Africa should work towards social justice and humanization. Some have seen digitalization as a process that has the potential to fight poverty and achieve sustainable goals set for 2030 [16]. De Vos [16] adds, "Digitalization and decolonization are opportune angles to approach this issue. The two concepts allow us to connect past, present, and future in a critical yet constructive and accessible manner. Decolonization promotes the cultivation of digital knowledge." Seen in this light, digitalization has a huge potential to liberate in terms of factors such as culture, history, self-expression and other epistemologies. Meaningful and progressive digitalization should be able to convert traditional text into computer friendly modes. Apart from the negativity associated with digitalization such as unequal distribution of digital technology that leads to digital divide, some are optimistic of the role of digitalization within decolonization. De Vos [16] opines:

[...] digital technology constitutes new creative freedom. It also creates an opportunity to take control of the narrative. Self-expression, advocacy, and socio-political engagement are facilitated and supported by digital means. Social media are the preferred platforms to drive anti-racist movements such as Black Lives Matter. The organization of the digital sphere offers tools for information exchange and networking in a coordinated yet decentralized manner. The innovativeness of digital technology gets also associated with economic development. 
Timmis and Muhuro [17] caution against using universalist mechanisms when we implement digitalization in African universities where students are very diverse. Furthermore, they argue that decolonization of universities should include rethinking the "technocratic consciousness" but this should take into cognisance rural students as they can only be successful digital practitioners if institutions of higher learning acknowledge previous digital experience and forms of knowledge. After magnifying the individual and collective agency they can focus on "supporting transitions, as mechanisms for shaping a decolonized digital education" [17].

Yet in South Africa it is not only the rural students who may struggle with digital education. Many students come from historically black schools and poor families where there was no social capital and technologized spaces may alienate many of these students, hence it is critical to involve them at all levels of transformation. Digital transitions are critical for many students who come from schools whose standards may be far below the expected. In another study Coop [18] found that rural universities lagged behind when it comes to digitalization. She found out that students from rural institutions were less prepared at the beginning of their university career. Coop [18] also declares that the digital literacies of graduates empower or hamper their capabilities and flexibility as lifelong learners in the future and these have a potential to magnify existing social inequalities. "This goes beyond the recognition of a 'digital divide'. It involves the study of digital inequalities reinforcing, and even exacerbating, existing social inequalities as pre-existing differences in human capital are transferred into online settings (DiMaggio \& Garip, 2012)" [18].

Distance education leaders have a huge task to accomplish in trying to lead fully digital institutions of higher learning to close the digital divide whilst serving the society. An institution such as the University of South Africa where this study was conducted is the biggest university in distance education in South Africa and has over 400000 diverse students worldwide. Lembani, Gunter, Breines and Dalu [19] postulate that those working in higher education should recognize that integrating digitalization in teaching and learning demands several resources which countless students may not have. Lembani et al. [19] add that distance education providers such as UNISA should acknowledge the varying contexts of students. Distance education leaders in such institutions should be wary of creating digital divide and concern should be around access and success for all students. Leaders need to realize also that diverse students have copious challenges given the history of a country like South Africa where many families are still in poverty and it is difficult to keep digital equity among students. In fact, the call for decolonization in distance higher education also means the ability of leaders to address the historical imbalances from colonial and apartheid legacies. In most cases even teachers need much retraining because they were educated under a system of Bantu Education which the educator Tabata [20] referred to as Education for Barbarism. Thus distance education cannot concentrate on Information Communication Technology (ICT) only but also on historical injustices and these include the redress of culture, history and knowledges. Furthermore, Jantjies [21] elucidates how COVID-19 has demonstrated that technology is an important element in education today although teachers, like their learners have varying digital skills. Numerous teachers and families cannot afford the high costs of data to uphold online learning. Jantjies [21] maintains that South African institutions should address digital inequalities in e-learning.

Warner [22] refers to digital decolonization as indigepedia. This means that the history of the indigenous people in Africa should be examined as living histories not as artifacts from the past. Digital archives should help the society understand and revitalize the traditions of the indigenes and help to answer the questions of indigenous peoples as they "speak back" to mainstream society to have their voices heard and respected [22]. Reformulating the South African curriculum, for example, will mean understanding the living histories of the indigenous peoples. The latter will be critical in using digital technologies in understanding the formulation of a relevant curriculum. Digital archives should help immensely in the improvement of scholarship to respond to present needs. Warner [22] aptly argues what should be the role of digital technologies during times of decolonization:

This digital archive could serve as tool to connect Indigenous communities and also serve as a way for non-Natives to see how Indigenous ways of knowing operate - this could help them to disrupt their common-sense understandings of education, citizenship, and community. Indigepedia, as a way of thinking about this Native curriculum intervention has the potential to be another tool of transformation. The power of this tool is that it can help to re-present Indigenous peoples and be a piece in the process of decolonization.

The higher education leader should then always try to see how the digital technologies could assist in engendering humanizing education rather than alienating education. Technologies should always be seen as a boon to the societies or communities serving them. In Africa transformation, it can be traumatic as the process of trying to transform Western education has demonstrated and now it has exerted more pressure on academics and students on how to embrace technologies. Effective institutions will formulate models that would be amenable to digital innovation. At UNISA the Department of Leadership and Transformation (formerly Change Management Unit) which operates in the Vice Chancellor's office utilizes Five Pillars of Change to inform the path of a transforming higher education institution. These Five Pillars of Change could be useful in working with the digital archive within a decolonizing atmosphere:

- African Scholarship (Curricular transformation that supports not only Western knowledges but African-centered knowledges as well);

- Changing the Institutional Culture (Changing ingrained beliefs and practices);

- Governance, Leadership and Management (University leadership using relevant strategies to lead change and transformation);

- Rethinking Systems (Restating the new roles of ICTs and Open, Distance and eLearning practices); and

- Promoting the Discourse for Change (Ensuring that continuous communication permeates the entire 
organization).

The above pillars work well with digital archive because they inform the kind of change that any university may need to embrace. Scholarship, institutional culture, governance will all inform the systems undergirded by the digital age. In turn, these will promote the discourse, and thus change and transformation will be debated across the organization.

\section{RESEARCH METHODOLOGY}

The sample in this qualitative study was selected through purposive sampling. Etikan et al. [23] and Brink [24] state that purposive sampling or judgmental sampling includes the deliberate choice of participants due to the characteristics the participants have. The researcher decides what needs to be known and she goes out to find people who have experience in that area [23]. At the time of the study I worked at the University of South Africa and all the eight participants worked at the same university hence I searched for people who were rich in relevant information on digitalization. Of the eight participants three were heads of department, three were directors, one a dean and one a deputy vice chancellor. Their characteristics are tabulated in Table II below.

\begin{tabular}{|l|l|l|l|l|}
\hline TABLE II: THE PARTICIPANTS' CHARACTERISTICS \\
\begin{tabular}{|l|l|l|l|l|}
\hline Participant & Position & Gender & Race & $\begin{array}{l}\text { Years at } \\
\text { UNISA }\end{array}$ \\
\hline 1 & $\begin{array}{l}\text { Head of } \\
\text { Department }\end{array}$ & Female & White & $>10$ \\
\hline 2 & $\begin{array}{l}\text { Head of } \\
\text { Department }\end{array}$ & Male & Black & $>10$ \\
\hline 3 & $\begin{array}{l}\text { Head of } \\
\text { Department }\end{array}$ & Female & Black & $>10$ \\
\hline 4 & Director & Male & White & $<10$ \\
\hline 5 & Director & Male & Black & $=10$ \\
\hline 6 & Director & Female & Black & $>10$ \\
\hline 7 & Dean & Male & Black & $<10$ \\
\hline 8 & $\begin{array}{l}\text { Dep } \\
\text { Vice-Chancellor }\end{array}$ & Male & Black & $>10$ \\
\hline
\end{tabular}
\end{tabular}

We interviewed the participants first individually and then used two focus group interviews of four participants each. Using two forms of interviews was to triangulate the data elicited. The qualitative data analysis included the classification and interpretation of linguistic material to make statements about implicit and explicit dimensions and structures of meaning making in the material and what is represented in it. According to Thorne [25] in qualitative research, relevant reality is that which takes place in subjective experience in social context and historical time. Furthermore, Thorne [25] states that qualitative researchers seek to uncover knowledge about the way people think and feel about the circumstances in which they find themselves. Constant comparative analysis was done as the researcher compared the responses from the participants with each other.

From the comparisons above emerging categories surfaced. Certain categories became more centrally focused - axial categories and possibly core category. Axial coding involves breaking down core themes relating codes to each other via a combination of inductive and deductive thinking. Scott and Medaugh [26] contend, "Axial coding requires researchers to continually modify and reshape their emerging conceptual framework as more data are examined. It results in a coding framework from which to synthesize and organize data into more coherent, hierarchically structured categories and subcategories."

We conducted the interviews in English and then later transcribed them. All eight participants had consented to be audiotaped during the interview sessions. After the data were transcribed the participants were given their transcribed individual responses to verify the veracity of the notes. The questions asked to the participants were semi-structured. These were appropriate in collecting open-ended qualitative data. Furthermore, we were able to dig deep into the thoughts and beliefs of the participants. The semi-structured interviews also encouraged two-way communication and the use of both close-ended and open-ended questions which elicited the participants' experience.

The questions asked were categorized under four themes:

1) Digital leadership

2) Technology in a transforming higher education

3) Decolonization, transformation and digitalization

4) Institutional culture and digitalization

\section{RESUlts}

Generally, the participants acknowledged the role of digital leadership in a transforming institution like the University of South Africa (UNISA). They said this talked to the vision of the university which is, "Towards the African University shaping futures in the service of humanity". All the participants spoke to this vision as they addressed the role of digital leadership in the context of decolonization and transformation. They also alluded to the strategy of the university based on the mission which spells out that UNISA seeks to serve society by promoting African perspectives that encompass quality as well as technologically-guided education. Furthermore, the participants contended that digital leaders would be effective if they were able to introduce a new institutional culture that would support quality distance and technological education. Furthermore, the participants reiterated the need for the university to innovate as it moves towards producing excellent research, scholarship and teaching. For the participants digitalization will be deemed effective if it supports student success rather than creates a stronger digital divide.

\section{A. Digital Leadership}

The participants demonstrated various ways in which leaders like themselves can lead digitalization at higher education institutions. All maintained that digital leadership's main focus should be to fuse it with the vision and culture of the university. Additionally, they pointed out that it should not only be managers who should lead the process. Participant 8 (P8) summarized this succinctly when he pointed out:

Innovation needs everybody to be involved and that is why we need good communication. When colleagues know what has to be done in leading digitalization, all of us can be digital leaders. It has to do with passion for without passion we cannot imagine any transformation in digitalization. We are a distance education, the biggest one in South Africa hence 
every lecturer and every employee must be a digital leader.

P3 concurred with P8 as she posited that:

Maybe we need more formalized programs where we are prepared to be digital leaders. I do not think this should be for university managers only, let us see everyone as managers of change. None of us are experts in this hence all should pull together. Given the nature of UNISA we all should be digital natives who can easily lead. What will be challenging though is the aspect of linking digitalization to decolonization. It is not easy for me and certainly it won't be easy for several colleagues.

Several other participants concurred about ways in which the decolonized debates need much attention and engagement of everyone. P8 stated that the challenge is that not everyone, including managers, understands decolonization the same way even though there have been workshops and seminars around the university. P8 pointed out that digitalization can be delayed if it is inextricably linked to decolonization because many are still learning the understanding of the concept. Yet P1 said that she has always linked digitalization to decolonization:

It is inevitable. We are in a time of decolonization hence we need to link teaching, learning and research to decolonization. If we are to lead this successfully we need to understand these dynamics. It is a challenge because remember, there is still a lot of faculty in Africa who are still daunted by technology. The paradox of COVID-19 is that it forced everyone to learn something about technology. That is what we need as we entertain the debates about decolonization.

Almost all the participants maintained that digitalization should not be a negotiable in an institution such as UNISA. Yet in preparation for UNISA Vision 2020 which, among others, stresses innovation and the creation of the African university, decolonization should be seen as part of the university's evolution towards adopting a new identity as an African university.

\section{B. Decolonization and Technology}

Participants saw the digitalization process as amenable to the university's five pillars of change as well as the university's eight dimensions of change. UNISA's five pillars include promoting African scholarship; changing institutional culture; rethinking governance; leadership and management; and rethinking systems as well as promoting discourse for change. The participants stated that pillars can be very useful for digitalization at UNISA. Many pointed out that rethinking systems is critical to digitalization at the university because "it speaks directly to technological advancement at the university." P4 declared:

All the five pillars are part of UNISA strategy because they inform strategy and vision. Therefore, when you look at the pillars you will find that they address a number of things and among these are decolonization, digitalization and the new institutional culture necessary to transform the university. Consummate digitalization demands that we follow such progressive university models that move us towards transformation and decolonization.

P5 and P2 were also vocal about the usefulness of the five pillars in introducing and sustaining "the digitalization agenda at UNISA," stating that UNISA has the template for transformation if only everyone can be a digitalization leader "or at least be a good follower who earnestly believes in change". Yet P4 and P7 whilst totally supporting the idea of the pillars are wary of using much theory which they state has a potential to confuse. $\mathrm{P} 7$ contended:

We have useful theory and as an institution we have a great strategy that supports our vision. But we should be careful of bombarding our employees with much theory because many are still resistant to decolonization or they simply don't understand it. Personally, I think we should pair digitalization with decolonization, but let us think of many who are not professionally matured to make the links.

Yet all the participants maintained that UNISA, firstly, being a distance education institution, cannot avoid digitalization and secondly, as an African university seeking relevance, it could not avoid decolonization and all the aspects contained in the Five Pillars model. They all concurred that the university needed to move with the times and if they are to be effective as a modern distance education institution, they have to have digitalization awareness drives throughout the university. P1 as well as P5, for example, highlighted the importance of working to change the consciousness of all the employees and students. P5 added that this is important "because if people are not ready mentally they cannot be digital leaders".

\section{Institutional Culture, Vision and Digitalization}

The participants were aware of the importance of university culture and vision in digitalization and decolonization of technology. Apart from the Five Pillars of Change, the university management has introduced what they refer to as the eight dimensions [27] Five of the participants saw the relevance of the eight dimensions when it comes to digitalization. The eight dimensions comprise of elements that are thought to be pertinent to transformation for they give the university a "map of transformation". The eight dimensions are:

- Staff equity, development and work experience

- Student equity, development and achievements

- Student living and learning experience, including their socialization in an ODeL context

- Knowledge, epistemology and language

- Governance, leadership and management

- Institutional culture and social inclusion

- Funding and resource allocation, including BBBEE

- Infrastructure, including facilities, buildings and ICTs

P7, P8 and P3 maintained that the dimensions are critical in digitalization and decolonization at the university. They pointed out that institutional culture as well as infrastructure, buildings and ICTs are relevant to digitalization. P6 said of the eight dimensions:

The digitalization process is about the change we are talking about here we envisage a future UNISA. If you look at the eight dimensions that we use they include quite a few things; vision, strategy, decolonization and most importantly, digitalization. As managers we cannot exclude the dimensions because they can guide us to be strong digital leaders. And these dimensions can prepare all the staff members here. 
The dimensions also answer the questions posed by the study in a number of ways. Firstly, the dimensions explicate knowledge that is found to be critical at UNISA when people face transformation. Secondly, the dimensions demonstrate the skills that they can share with fellow employees in the creation of a university guided by excellence.

One of the major factors that the participants see technological changes transforming is interaction at the university. Participants 2, 6 and 7 emphasized that technological changes have a huge contribution to make in minimizing isolation. They stated that it is critical today to make use of virtual communities that would enhance learning in a digital environment. Participant 1 succinctly put it:

One of the cultures that our institutions are used to is the absence of virtual communities that would ensure that faculty form teams in enhancing teaching. This is very necessary for the students as well who may soon find out the importance of models such as heutagogy where the idea of virtual communities are critical. This mean changing the cultures of how we used to do things in our institutions. Without intent managers, this change of culture cannot be attained. Where one speaks of reclaiming the university or rethinking the university - both refer to one thing and that is changing the institutional cultures.

In addition to the above, the participants argued that leading a culture that embraces technology requires management that is sensitive to the training of both staff and students. The student profile at the university is changing and several students come straight from poor high schools that have no computers and therefore when they get to the university they are not able to use the technology at a fair level. Furthermore, participant 4 pointed out that sometimes lecturers are hired from contact universities and find themselves in a distance education environment with no preparation for a distance education institution culture.

In focus group interviews, the participants highlighted the need for university management to ensure that the digital archive ensures that technology supports critical thinking. Furthermore, they also concurred that technology should be supported if it is used to support social justice initiatives. All the participants shared their ideas about students who live in remote areas - usually rural - who may not have Wi-Fi or the internet. They pointed out that the latter makes it difficult for some students to be part of learning in a higher education institution. Therefore, all concurred that technology should minimize the gap between the remote students in marginal places and those who are in the cities.

The participants pointed out that a digital archive should help in the improvement of teaching and critical thinking skills. Effective research will improve the quality of students, as well as that of staff, knowledge management and success. Furthermore, P5 argued that decolonization needs constant relevant research. This director argued:

Leadership matters when it comes to research especially now when universities are facing the challenge of introducing decolonized and relevant curricula.

Participant 8 concurred when she pointed out that the digital archive should do two things:

On the one hand, it should help the academic to be able to source out references in an easy manner that is user friendly.
On the other, it should first equip the manager who in turn should use it to enhance the skills of other colleagues. We usually experience the loneliness of research where a few lecturers work in isolation to conduct their research. The virtual communities should expand the role of research teams in a time of digital surge.

\section{DISCUSSION}

The participants in the study all understood the urgency and need for digitalization of their institution, UNISA. They also understood why UNISA needed digitalization to be a leader in open and distance education in South Africa. They also maintained that given the nature of the university it would not make sense if the institution did not respond adequately to digitalization. Digitalization for the participants meant transforming the institutional culture and systems of the university. They consented to the idea of digital leadership as many maintained that any higher education institution serious about transformation should begin with a community of professionals who understand how digitalization could change scholarship, governance and research, as well as support the decolonial agenda which was supported by the university. All the participants believed that every colleague needed to be a digital leader and this was critical in ensuring that digitalization seeps through the organizations. There was also a sense of perceiving everyone as a leader and a manager of change. Like various other South African universities, UNISA was discussing decolonization of the university hence the participants also sought to see how digitalization fitted into the decolonial debates. The idea of decolonization also brought up the questions of social justice and how digitalization would close the digital divide. In fact, the participants reiterated the transformation path the university was taking and they highlighted the importance of two documents that were frequently discussed in transformation debates at various university platforms. The participants maintained that digitalization would be methodical, more strategic and inclusive of decolonization if it included the following models in Fig. 1 which make up the critical elements for successful digitalization; Eight Transformation Dimensions and the Five Pillars of Transformation. See Fig. 1 below:

The participants concurred that the two combined models above; the Five Pillars of Transformation and the Eight Dimensions of Transformation, adopted and utilized by the university are pivotal in supporting digitalization. They also believed that digitalization and decolonization will not work if they do not connect with these models which are like the "grand plan" of transformation at UNISA. The two models include a number of elements that imbue the university with a strategic chart to tackle transformation initiatives. The models also contain a number of factors mentioned by the participants in various ways and these include the necessary change to institutional culture, rethinking of infrastructure including ICTs, and seeing a link between epistemology and digitalization. The five pillars of transformation are all critical to the digitalization of the university. The five pillars also summarize what the university is all about and these give the ecological picture of the institution. What the participants 
alluded to was that the two models help in minimizing confusion in the midst of transformation. Furthermore, there is also a sense of believing that without guiding principles the university may not be able to attain its transformation goals, including those of digitalization and decolonization.

\begin{tabular}{|} 
FIVE PILLARS OF TRANSFORMATION \\
1. Transforming Scholarship \\
2. Transforming Institutional Culture \\
3. Rethinking Systems and Policies \\
5IGITAL LEADERSHIP \\
5. Discourse for Change \\
EIGHT TRANSFORMATION DIMENSIONS \\
1. Staff equity, development and work experience \\
2. Student Equity, Development and Achievements \\
3. Student Living and Learning Experience \\
4. Knowledge, Epistemology and Language \\
5. Governance, Leadership and Management \\
6. Institutional Culture and Social Inclusion \\
7. Funding and Resource Allocation \\
8. Infrastructure, Including facilities, Buildings and ICTs \\
1 1 1 \\
Digitalization Decolonization
\end{tabular}

What is evident in the study is the realization of Table I which is Mays' table showing how the university has moved from the initial correspondence university it was in the early years. From this study I add the sixth generation which is digitalization and decolonization generation and it demonstrates how the university has shifted into a globalizing institution that strives to center African knowledges as well. From what the participants said, UNISA is moving towards a stage where it is operating in a complex digital period of what Wa Thiong'o [28] refers to as "globalectics". This term refers to interconnectedness and it also alludes to wholeness and equality of potentiality of parts. Figure 1 above shows this interconnectedness between several factors at the university. Additionally, the participants demonstrate the importance of collaboration and sharing power when it comes to digital leadership necessary to steer the sixth generation.

\section{CONCLUSION}

This case study demonstrates how important it is to develop and empower digital leaders in a transforming African university. As the participants stated it is critical to ensure that all colleagues play a critical role in leading transformation. The study showed that knowing and understanding university policies plays a critical role as faculty seeks to understand the paths taken by digitalization. At UNISA the understanding of models such as the five pillars of transformation as well as the eight dimensions of Transformation is very crucial in understanding digitalization and decolonization.
Faculty members should be in the forefront of digitalization because when transformation initiatives are tackled by teams it is easy for the initiatives to be communicated across the institutions. The participants in this study demonstrate that any transformation needs to be led and the participants embraced the idea of perceiving that it was every faculty member's duty to lead the change process when it comes to digitalization. Therefore, everyone has a critical role to play in the age of digital transformation and decolonization. Yet, educational transformation will stall in higher education institutions if leaders are not thoroughly prepared for change initiatives themselves. Conscientious educational leaders will want to maximize the use of technology for ensuring not only access but throughput success as well. The South African universities experience a myriad of challenges and if the digital age could solve many of them it is creative leaders who will determine that. Distance education institutions such as UNISA have to constantly think carefully and critically how technology can be maximized. Finally, qualitative studies have limitations because the results cannot be generalized but the study offered an understanding of this particular case. It is clear that educational leaders in higher education institutions need to know their roles in enhancing access and success in their institutions. Furthermore, with the calls for decolonized transformed universities in South Africa, the role of leaders has never been so critical in guiding and understanding change initiatives. As educational leaders in the transforming institutions think about the digital age that has enmeshed the university they have to think of how the university can improve internalized cultures, enhance critical thinking skills of role-players and improve research and teaching. Technology should improve communities as leaders try to build responsive and relevant institutions. Conscientious leaders should also know how to follow vision guided change initiative goals.

\section{CONFLICT OF INTEREST}

The author declares no conflict of interest.

\section{REFERENCES}

[1] M. Beaudoin, "Distance education leadership for the new century," Online Journal of Distance Learning Administration, vol. 6, no. 2, 2003.

[2] V. Msila, "Massification: Preparing faculty for open learning systems," Progressio, vol. 28, no. 1\&2, 2006.

[3] T. Mays, "From policy to practice: an evaluation of the Unisa National Professional Diploma in Education from the perspective of social critical theory," MEd dissertation, Pretoria: UNISA, 2004.

[4] A. Mason, The Making of a Distance Learning University, Pretoria: Unisa Press, UNISA 1873-2018, 2018.

[5] B. S. Ngcamu, "Digitalizing South African universities: Exploring benefits, barriers and risks," Intechopen, 2018.

[6] R. Goethals, G. Sorenson, and J. B. MacGregor, "Leadership in the digital age," Encyclopaedia of Leadership, 2002.

[7] T. Zupancic, J. Verbeke, H. Achten, and A. Herneoja, "Digital leadership, complexity, simplicity," presented at eCSSDe $34^{\text {th }}$ Conference. 2016.

[8] N. Urbach and M. Roglinger, "Introduction to digitalization cases: How organizations rethink their business for the digital age," Digitalization Cases, Bayreuth: Springer, 2019.

[9] A. Schumacher, W. Sihn, and S. Erol, "Automaton, digitization and digitalization and their implications for manufacturing processes," presented at International Scientific Conference, Bucharest, Romania, October, 28/29, 2016. 
[10] J. E. Chukwuere, "From decolonisation to digitalisation of education in South Africa," Ponte Academic Journal, vol. 73, no. 12, pp. 232- 241, 2017.

[11] S. Heleta, "Decolonisation of higher education: Dismantling epistemic violence and eurocentrism in South Africa," Transformation in Higher Education, vol. 1 no. 1, 2016

[12] V. Msila, "Preface: Liberating education," Developing Teaching and Learning in Africa: Decolonising Perspectives, Stellenbosch: Sun Press, 2020.

[13] R. Risam, "Decolonizing the digital humanities in theory and practice," English Faculty Publications, vol. 7, 2018.

[14] A. Dirksen, "Decolonizing digital spaces," Remarks Delivered at the Principal's Symposium: Imagining our Digital Future at Queen's University on November 26, 2018.

[15] I. Holev, "Decolonize the internet," Latitude, 2019

[16] S. D. Vos, "Decolonizing digitals: 0-1 for Africa: Digitalization and decolonization from an Africanistic perspective - An analysis," Masters Dissertation, Ghent (Belgium): Ghent University, 2020.

[17] S. Timmis and P. Muhuro, "De-coding or de-colonising the technocratic university? Rural students' digital transitions to South African higher education," Learning, Media and Technology, vol. 44 no. 3, pp. 252-266, 2018.

[18] T. Coop, "Students in South Africa: perspectives on digital technology and online learning provision in HE," The Unbundled University: Researching Emerging Models in an Unequal Landscape, July 2, 2018.

[19] R. L. Lembani, A. Gunter, M. B. Breines, and M. T. B. Dalu, "The same course, different access: the digital divide between urban and rural distance education students in South Africa," Journal of Geography in Higher Education, vol. 44, no. 1, 70-84, 2020.

[20] I. B. Tabata, Education for Barbarism, London: Unity Movement of South Africa, 1979.

[21] M. Jantjies, "How South Africa can address digital inequalities in e-learning," The Conversation, April 29, 2020.

[22] D. P. Warner, "Indigepedia: Digital decolonization - Living histories of native American peoples indigenizing K-12 curriculum in
Washington State," Doctoral Dissertation, Washington: Washington State University, 2012.

[23] I. Etikan, S. A. Musa, and S. Alkassim, "Comparison of convenience sampling and purposive sampling," American Journal of Theoretical and Applied Statistics, vol. 5, no. 1, pp. 1-4, 2016.

[24] H. Brink, Fundamentals of Research Methodology for Healthcare Professionals, Kenwyn: Juta, 2000.

[25] S. Thorne, "Data analysis in qualitative research," Evidence Based Nursing, 2000

[26] C. Scott and M. Melissa, "Axial coding," The International Encyclopedia of Communication Research Methods, 2017.

[27] V. Msila, "From epistemic violence to a transformed institution University of South Africa's change management unit's endeavours to traverse transformation paths," INTED2019 Proceedings, Valencia, Spain, 2019

[28] N. W. Thiong'o, Globalectics: Theory and the Politics of Knowing, New York: Columbia University Press, 2014.

Copyright $(\odot 2021$ by the authors. This is an open access article distributed under the Creative Commons Attribution License which permits unrestricted use, distribution, and reproduction in any medium, provided the original work is properly cited (CC BY 4.0).

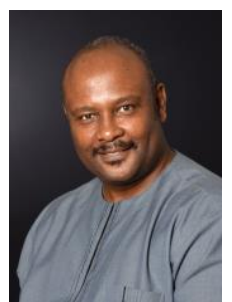

Vuyisile Msila was born in Port Elizabeth in the Eastern Cape province in South Africa. He studied at Vista University, University of Cape Town, Nelson Mandela University and Michigan State University where he was a fulbright fellow. His doctoral qualification is in educational management.

He is a researcher rated $\mathrm{C} 2$ by the National Research Foundation (NRF). $\mathrm{He}$ is the recipient of the Chancellor's Prize in Research in 2012 at UNISA. His interests include educational leadership, decolonization, politics of education and open learning. Prof Msila has published extensively on these areas. 